\title{
DE LO RESCATABLE DE LA SOCIOPOLITICA. GENESIS FILOSOFICA DE LAS TEORIAS DEL PASO AL ACTO
}

\section{WHAT RECOVERABLE OF SOCIOPOLITICAL. GENESIS OF PHILOSOPHICAL THEORIES OF PASSAGE TO THE DEFLECTED ACT}

\author{
Jorge Morales Manzur ${ }^{1}$ \\ Juan Carlos Morales Manzur ${ }^{2}$ \\ María A. Fernández ${ }^{3}$
}

\section{Resumen}

El presente papel de trabajo tiene como objetivo el de describir y analizar la génesis por la que ha atravesado el pensamiento filosófico criminológico partiendo de la base clásica positivísta hacia el desarrollo del positivismo estructuralista en una delimitación de la parte que trata de manera dogmática las teorías del paso al acto. Lo que se busca es llevar al lector por un recorrido dogmático por los modelos científicos que han explicado la conducta desviada y criminal como modelo referencial frente a los dictámenes y regulaciones de la ciencia penal, abordándola como un todo, por ello se resalta la primera etapa de las escuelas sociológicas en sentido estricto y como esta en su practica desencadenó una serie de movimientos intelectuales que llevan a la codificación formal de las teorías del paso al acto criminal. Observándose a su vez, que la misma se presenta de manera didáctica y simple para la consulta de quien este interesado en conocer sus inicios y su trayectoria por los caminos dogmáticos y filosóficos. A esto se le adosan comentarios para su mejor comprensión de las avances y bemoles del la misma.

Palabras Claves: Escuelas Sociológicas, Estructural Funcionalismo, Anomia, Grupos Referenciales, Modo de Adaptación.

\begin{abstract}
This working paper aims to describe and analyze the genesis for which has passed through the criminological philosophical thought based on the classic positivist basis to the development of structuralism positivism in a delimitation of the part dealing with theories dogmatically passage to the act. What is sought is to take the reader on a dogmatic journey of scientific models which explain the deviant and criminal behavior as a reference model against the rulings and regulations of criminal science, approaching as a whole, so the first step is highlighted sociological and strictly schools like this in your practice triggered a series of intellectual movements that lead to the formal codification of the theories of the transition to a criminal act. Observed in turn, that it is presented in a didactic and simple way to query who is interested in knowing their beginnings and his career by dogmatic and philosophical paths. To this it is abut comments for better understanding of the progress and flats of it.
\end{abstract}

Keywords: Sociological Schools, Structural Functionalism, Anomie, Reference Groups, Adaptation Mode.

\footnotetext{
1 Doctor en Derecho. Magíster en Ciencias Penales y Criminológicas. Investigador del Instituto de Criminología de LUZ, Universidad del Zulia. E-mail: jnmm70@hotmail.com

2 Doctor y Magíster adscrito a la Facultad de Ciencias Jurídicas y Políticas, Universidad del Zulia. E-mail: jcmmanzur@hotmail.com

${ }^{3}$ Magíster en Ciencias Penales y Criminológicas y Abogado. Investigadora del Instituto de Criminología de LUZ. Facultad de Ciencias Jurídicas y Políticas, Universidad del Zulia. E-mail: marialeja24@hotmail.com
} 


\section{INTRODUCCIÓN}

La Criminología como disciplina del área social, se ha dedicado al estudio de varias áreas del conocimiento que han cambiado en razón de la posición doctrinaria en la cual nos encontremos frente a los distintos paradigmas epistemológicos que han explicado el problema criminal. Nos referimos al positivismo criminológico, el interaccionismo simbólico y la criminología critica.

Su vinculación con el Derecho es innegable, ya que el mismo es fuente originaria de discusiones académicas y objeto de su estudio. Las instituciones propias del derecho penal son generadoras de delito y las funciones que cumplen las penas han sido harto discutidas tanto por la doctrina como por las reuniones mas álgidas en materia de criminología. Ahora bien, dentro de las diversas ramas que integran o dividen la criminología se encuentran la llamada criminología organizacional que es aquella que se dedica al estudio de las teorías del paso al acto criminal. Así mismo, las teorías del paso al acto criminal se pueden clasificar en las que se entienden en la estricta acepción sociológica y las que se estudian en su alcance estructural funcionalista. Dependiendo del punto de vista de la observación, eso es, el hombre frente a la sociedad o la influencia de ésta sobre las personas, será la consideración o punto de vista que divide la concepción de la sociopolítica.

En opinión de Lola Aniyar de Castro (1976) la llamada criminología liberal y organizacional, es aquella que se dedica principalmente al estudio de la lucha contra el crimen y por la reforma del aparato de control, especialmente el preventivo y con marcado interés en los procedimientos de prevención general como lo son mejores condiciones de vida, educacionales, habitacionales, de acceso al trabajo, alimenticias, sanitarias, entre otros.

Las teorías sociológicas son también denominadas TEORÍAS DEL PASO AL ACTO CRIMINAL. Para esta corriente criminológica, su función legitimadora está sustentada en la hipótesis de que el sistema imperante es el adecuado y que lo que se requiere es corregir las fallas en su funcionamiento.

Las escuelas sociológicas, para Lola Aniyar de Castro (1976) también se caracterizan por "su insistencia en el estudio de la delincuencia de la clase baja, al aceptar sin discusión las definiciones delictivas proporcionadas por los códigos penales; al haber ignorado las relaciones estructurales, el funcionamiento del poder y las definiciones de la clase, se están inscribiendo en el modelo consensual del Estado, en la aceptación de lo establecido y en la línea de investigación causal explicativa de la escuela positivista". 
Las teorías sociológicas del paso al acto criminal tratan de explicar sociológicamente el porque ocurre el delito. Dentro de las teorías que conforman la escuela sociológica se puede hablar de dos grandes tendencias, a saber, una que se refiere a la acepción sociológica en strictu sensu y la otra, el enfoque estructural funcionalista. La escuela sociológica en strictu sensu, que es la que estudia la relación del sujeto hacia la sociedad y la escuela sociológica estructural funcionalista, que es aquella que estudia las relaciones del individuo como consecuencia de la estructura y funcionamiento de la sociedad y que muchos autores llamaron organizacional.

En el presente trabajo, en primer lugar se estudia la escuela sociológica de Emile Durkheim quien se dedicó al estudio de la criminalidad en la fase inicial del positivismo, este autor, sostiene que el delito es un fenómeno normal de la sociedad. Por lo tanto, el delito existe en todas las sociedades de cualquier tipo que sean, y aunque cambie de formas. Para este sociólogo, no existe ninguna sociedad conocida, en la que bajo distintas modalidades o formas, su legalidad no sea violentada; que sus leyes no sean transgredidas y, agrega, que él considera que en una sociedad cuando se están violentando sus normas, también se esta violentando su moralidad. Esto quiere decir, que este autor responde a aquellos postulados que sostienen que no es corriente la trasgresión de las normas y el sostiene que eso es incorrecto en razón de que la sociedad es resquebrajada constantemente. También, hay que acotar que Durkheim fue el primero en acuñar el termino anomia y se explica en el desarrollo del contenido como este sociólogo planteaba el problema del anomia, también, se hace referencia a las que para el constituyen las causas del delito, a los tipos de suicidios que Durkheim plantea, especialmente al suicidio anómico.

El segundo aparte del trabajo esta dedicado al estudio de la llamada Teoría Ecológica desarrollada por la llamada Escuela de Chicago. Esta teoría se desarrolla en la época del Laissez Faire, época del nuevo estilo de vida americano. En esta teoría, también se hace referencia a la llamada comunidad ecológica. Hay a su vez que acotar, que estos estudiosos de la escuela de Chicago, se dedicaron al estudio de la delincuencia juvenil y para ello realizaron un análisis multifuncional, al mismo tiempo que correlacionaron el comportamiento, el grupo socio - cultural de procedencia y la zona en la que se realizaron los llamados actos desviados. Los autores Shaw y Mckay también hablan, de círculos concéntricos como zonas de clara diferenciación social y económica, del centro, de la llamada zona de desorganización social y concluyen entre otras cosas, que existen zonas conflictivas donde se aprenden y se difunde la conducta desviada.

En tercer lugar, se estudia el Ilamado Enfoque Estructuralista desarrollado por Selling en donde se plantea que el problema cultural es incompatible con la adaptación social y esta es la 
razón de la desviación de la conducta. También hace referencia a la ciudad grande como refugio para todos, al surgimiento de pequeños grupos culturales. Este autor señala que los conflictos culturales son consecuencia normal del proceso de diferenciación social, la sociedad produce grupos marginales provocando conductas que salen de lo socialmente establecido. Selling, por su parte, se acoge al concepto de Diferenciación Social.

Posteriormente, se estudia la llamada Teoría de la Asociación Diferencial planteada por Edwin Sutherland quien señala entre otras cosas, que las condiciones que originan el delito deben estar presentes cuando el delito este presente. Sutherland, busca explicar el comportamiento criminal a través de lo que él denominó Teoría de la Asociación Diferencial y para ello parte de la concepción culturalista de desorganización social. También, señala que el comportamiento desviado, tiene un origen particularmente social. Sutherland sostiene también, que al considerar los factores que conllevan a la comisión de un hecho punible hay que hacer referencia a los factores que operan en ese momento. Sutherland por otro lado, otorga gran importancia a la distinción entre conducta delictiva y conducta no delictiva, habla de diversos tipos de explicaciones sobre la conducta delictiva, también, realiza una explicación genética de la conducta delictiva. Sutherland, concluye que el elemento generador de la subcultura criminal es esencialmente social porque a pesar del complejo histórico social que tiene cada individuo, la asociación diferencial esta dentro del ámbito social. Sostiene a su vez, que el índice delictivo elevado, es producto de lo que él denomina organización social diferencial la cual en su opinión se caracteriza a su vez por ser integradora.

Seguidamente se estudia a Robert Merton y su Teoría de la Anomia. Merton, reformula y amplia el concepto de Durkheim, y trata de explicar no sólo el suicidio, sino también una serie de conductas como el delito, la enfermedad mental, el alcoholismo, la toxicomanía, y también la conducta burócrata y del revolucionario, utilizando el vocablo "anomia". En esta parte, también se hace referencia al contexto histórico imperante en el momento en el cual Merton desarrolla su teoría, a la notable influencia que ejerció Parsons en el autor y que se observa en la teoría de la anomia, a las influencias ideológicas presentes en la teoría, a las formas en que Merton divide la estructura social, a la forma en que autor concibe a la sociedad y a las teorías de alcance medio, a la relación entre metas y medios para el surgimiento de la anomia, a las formas de adaptación que Merton denomina: conformismo, innovación, ritualismo, retraimiento y rebelión, y se concluye esta parte haciendo referencia a la importancia de la teoría de la Anomia plateada por Merton. 
Luego de la Teoría de la Anomia de Merton, se pasa a estudiar la llamada Teoría de las Subculturas Criminales en donde Albert Cohen hace referencia a que el tema central de estudio de esta teoría es la criminalidad en los grandes centros urbanos. Se hace referencia a los conceptos de desorganización social, retraso cultural y marginalidad. Caracteriza también a esta teoría, el hecho de cuestionar el principio de culpabilidad de las escuelas clásicas y positivistas. Se observa también, que para esta teoría no existe un único sistema oficial de valores sino una serie de subsistemas que se transmiten a los individuos. Hay que acotar, que Cohen, limita su estudio a jóvenes delincuentes provenientes de las clases obreras. Se habla en esta parte igualmente sobre lo que Cohen denominó Forma Reactiva, a que la subcultura de los jóvenes es diferente a la de los adultos, al concepto de cultura, a lo que representan las subculturas dentro de la cultura, a las observaciones sobre las cuales Cohen sustenta su estudio, al rol del sujeto en la estructura social, a la necesidad e importancia del grupo de referencia, al hecho de que el rechazo afianza la referencia, a los efectos de la nueva solución subcultural, a las características que para Cohen presenta la subcultura delincuente. Igualmente, se hace referencia tanto al acto delictivo como al acto desviado, a la subcultura delincuente y a la solución delincuente, a las funciones de la respuesta delincuente y al sistema delincuente de valores.

Y para concluir, se estudia la llamada teoría de las estructuras de oportunidad diferencial planteada por Richard Cloward y Lloyd Ohlin, en la cual se estudian las bandas juveniles en base a las oportunidades que la sociedad les brinda para obtener las metas sociales por ella fijada y limitan su estudio a las zonas e individuos de los sectores mas bajos. Se analizan las causas que llevan a la formación de las subculturas delincuentes, también se hace referencia a las diferencias entre aspiraciones y oportunidades legitimas, a los canales para ganar status, a la evolución de la subcultura delincuente, a los medios ilegítimos y la subcultura delincuente, a la influencia del medio social en la respuesta desviante, a la diferenciación subculturas y los tipos de subcultura delincuente (criminal, conflictiva y evasora) y a la persistencia y cambio de la subcultura delincuente.

Luego se encuentra las referencias bibliográficas, hemerográficas y digitales en que se ha sustentado la investigación. 


\section{LA SOCIOPOLITICA EN EL ESTUDIO DEL COMPORTAMIENTO DESVIADO}

\section{Del paso de la escuela positivísta a las escuelas del paso al acto}

González Vidaurri y Sánchez Sandoval (2005) afirman que con el advenimiento del positivismo, del Darwinismo y el gran avance de la antropología, los estudios del delito se dirigieron hacia una nueva categoría de hombre, el hombre delincuente, aquel determinado a serlo por factores biológico - evolutivos. Según esta visión, la teoría del delito carece de importancia, pues no se trata del análisis abstracto de las definiciones jurídicas, sino que el objeto de estudio debe ser solo el delincuente, como sujeto a juzgar, no con relación a la gravedad del delito como lo harían los clásicos, sino a su peligrosidad como individuo en sí y malvado, para la sociedad.

Dentro de este pensamiento, en lugar de aplicar penas determinadas se debían aplicar medidas de defensa social, acordes a la peligrosidad del sujeto y que debían mantenerse hasta que esa peligrosidad cesara. Esas "medidas de defensa social" que sustituirían a la pena debían ser adecuadas a la personalidad bio - psíquica del culpable, teniendo en cuenta las medidas socio ambientales. El punto de partida de toda medida penal era la peligrosidad del delincuente. La escuela clínica se opuso rotundamente al argumento del libre albedrío en razón de que, para ellos, el sujeto criminal se encuentra claramente determinado, diferenciándose delincuentes de no delincuentes, fundamentalmente, por factores antropológicos, sociológicos y psicológicos.

Aniyar de Castro (2005) afirma que la Criminología científica que existió fue la Clínica, para quien el delincuente es un enfermo, un paciente y el lenguaje médica que se utiliza de diagnóstico, pronóstico y tratamiento tiene que ver con la consideración del delincuente como un enfermo. Y va a haber para el paciente una interdisciplina centrada o enfocada sobre la personalidad, la manera de ser y comportarse de una persona, no sale de este mundo del individuo que está estudiando, es un caso clínico.

La consecuencia teórica de la criminología clínica positivista, es que la criminología se ve como una ciencia auxiliar del Derecho Penal. Para ellos, la criminología era auxiliar o subordinada al Derecho Penal, porque la criminología no podía estudiar nunca nada que no estuviera en el Derecho Penal. Es decir, que como no criticaba o cuestionaba el orden penal dado en los Códigos Penales que provenían de un contrato social, entonces, lógicamente estaba subordinada a lo que los Códigos Penales establecieran.

Es sabido que la Escuela positivista del Derecho Penal influyó en la mayoría de los ordenamientos jurídicos de Europa y América Latina, introduciendo en ellos las Ilamadas "medidas 
de seguridad" y los denominados "sustitutos penales" que podían ser aplicados en forma alternativa o paralelamente a la pena, en función de la peligrosidad social. La pena debería ser impuesta tomando en cuenta las características individuales y las condiciones ambientales que actuaron para motivar al sujeto a cometer el delito. Estos puntos de vista, abrieron el camino del contemporáneo concepto de individualización de la pena y de la individualización del tratamiento para socializar al delincuente.

Algunos autores afirmaban que el criminólogo trabajaba en una remota base militar, los criminólogos clínicos positivistas trabajan en su oficina diciendo quienes son los buenos y quiénes son los malos pero lo dicen según lo establecido en el Código Penal. Como el que viola el Código Penal es malo, entonces en la medida en que estudies al malo estas colaborando en esa guerra con los que están sometidos a través de las investigaciones y teorías criminológicas. Por eso, luego de cierto tiempo se cuestiona también el rol de la criminología y se afirma que el criminólogo se había convertido en una especie de guardián del zoológico de la desviación.

\section{CRIMINOLOgÍA POSITIVISTA QUE ESTUdIA A LA SOCIEDAD: ESCUELAS SOCIOLÓGICAS O TEORÍAS DEL PASO AL ACTO}

Dentro de las diversas ramas que integran o mejor dicho en las que se ha dividido la criminología se encuentran la llamada criminología organizacional que es aquella que se dedica al estudio de las teorías del paso al acto criminal. En opinión de Lola Aniyar de Castro (1976) la llamada criminología liberal y organizacional es aquella que se dedica principalmente al estudio de la lucha contra el DELITO y por la reforma del aparato de control, especialmente el preventivo y con marcado interés en los procedimientos de prevención general como lo son las mejores condiciones de vida, educacionales, habitacionales, de acceso al trabajo, alimenticias, sanitarias, entre otros. Las teorías sociológicas son también denominadas TEORÍAS DEL PASO AL ACTO. Para esta corriente criminológica, su función legitimadora está sustentada en la hipótesis de que el sistema imperante es el adecuado y que lo que se requiere es corregir algunas fallas en su funcionamiento.

Las escuelas sociológicas, para la autora Lola Aniyar de Castro (1976) también se caracterizan por:

Su insistencia en el estudio de la delincuencia de la clase baja, al aceptar sin discusión las definiciones delictivas proporcionadas por los códigos penales; al haber ignorado las relaciones estructurales, el funcionamiento del poder y las definiciones de la clase, se están inscribiendo en el modelo consensual 
del Estado, en la aceptación de lo establecido y en la línea de investigación causal - explicativa de la escuela positivista.

Dentro de las teorías que conforman la escuela sociológica se puede hablar de dos tendencias a saber: una que se refiere a la escuela sociológica en estrictus sensus y la otra es la escuela sociológica que responde al enfoque estructural funcionalista.

LA ESCUELA SOCIOLÓGICA ESTRICTUS SENSUS, que es aquella que estudia la relación del sujeto hacia la sociedad.

LA ESCUELA SOCIOLÓGICA ESTRUCTURAL FUNCIONALISTA es aquella que estudia las relaciones del individuo como consecuencia de la estructura y funcionamiento de la sociedad y que muchos autores llegaron a llamar organizacional.

En primer lugar, se estudiará la escuela sociológica de Emile Durkheim quien se dedicó al estudio de la criminalidad en la fase inicial del positivismo, este autor sostiene que el delito es un fenómeno normal de la sociedad. Por lo tanto, el delito existe en todas las sociedades de cualquier tipo que sean, y aunque cambie de formas. No existiría ninguna sociedad conocida, en la que bajo distintas modalidades o formas, su legalidad no sea violentada; que sus leyes no sean transgredidas $y$, agrega, que él considera que en una sociedad cuando se están violentando sus normas, también se está violentando su moralidad. Esto quiere decir, que este autor responde a aquellos postulados que sostienen que no es corriente la trasgresión de las normas y el sostiene que eso es incorrecto en razón de que la sociedad es resquebrajada constantemente. Hay que acotar que Durkheim fue el primero en acuñar el término anomia y se explica en el desarrollo del contenido como este sociólogo planteaba el problema del anomia, también, se hace referencia a las que para el constituyen las causas del delito, a los tipos de suicidios que Durkheim plantea, especialmente al suicidio anómico; La segunda teoría en estudio es la llamada Teoría Ecológica desarrollada por la llamada Escuela de Chicago.

Esta teoría se desarrolla en la época del Laissez Faire, época del nuevo estilo de vida americano. En esta teoría, también se hace referencia a la llamada comunidad ecológica. Hay a su vez que acotar, que estos estudiosos de la escuela de Chicago, se dedicaron al estudio de la delincuencia juvenil y para ello realizaron un análisis multifuncional, al mismo tiempo que correlacionaron el comportamiento, el grupo socio - cultural de procedencia y la zona en la que se realizaron los llamados actos desviados. Los autores Shaw y Mc Kay también hablan, de círculos concéntricos como zonas de clara diferenciación social y económica, del centro, de la llamada zona de desorganización social y concluyen entre otras cosas, que existen zonas conflictivas donde se aprenden y se difunde la conducta desviada. 
En tercer lugar, se estudia el llamado Enfoque Estructuralista desarrollado por Selling, en donde se plantea que el problema cultural es incompatible con la adaptación social y esta es la razón de la desviación de la conducta. También hace referencia a la ciudad grande como refugio para todos, al surgimiento de pequeños grupos culturales. Este autor señala que los conflictos culturales son consecuencia normal del proceso de diferenciación social, la sociedad produce grupos marginales provocando conductas que salen de lo socialmente establecido.

Selling, por su parte, se acoge al concepto de diferenciación social. Posteriormente, aparece la llamada Teoría de la Asociación Diferencial planteada por Edwin Sutherland quien señala entre otras cosas, que las condiciones que originan el delito deben estar presentes cuando el delito este presente. Sutherland, busca explicar el comportamiento criminal a través de lo que él denominó Teoría de la Asociación Diferencial y para ello parte de la concepción culturalista de desorganización social. También, señala que el comportamiento desviado, tiene un origen particularmente social.

Sutherland sostiene también, que al considerar los factores que conllevan a la comisión de un hecho punible hay que hacer referencia a los factores que operan en ese momento. Sutherland por otro lado, otorga gran importancia a la distinción entre conducta delictiva y conducta no delictiva; habla de diversos tipos de explicaciones sobre la conducta delictiva, también, realiza una explicación genética de la conducta delictiva. Sutherland, concluye que el elemento generador de la subcultura criminal es esencialmente social porque a pesar del complejo histórico social que tiene cada individuo, la asociación diferencial esta dentro del ámbito social. Sostiene a su vez, que el índice delictivo elevado, es producto de lo que él denomina organización social diferencial la cual en su opinión se caracteriza a su vez por ser integradora.

Seguidamente se estudia a Robert Merton y la Teoría de la Anomia. Merton, reformula y amplia el concepto de Durkheim, y trata de explicar no sólo el suicidio, sino también una serie de conductas como el delito, la enfermedad mental, el alcoholismo, la toxicomanía, y también la conducta burócrata y del revolucionario, utilizando el vocablo "anomia". En esta parte, también se hace referencia al contexto histórico imperante en el momento en el cual Merton desarrolla su teoría, a la notable influencia que ejerció Parsons en el autor y que se observa en la teoría de la anomia, a las influencias ideológicas presentes en la teoría, a las formas en que Merton divide la estructura social, a la forma en que autor concibe a la sociedad y a las teorías de alcance medio, a la relación entre metas y medios para el surgimiento de la anomia, a las formas de adaptación que Merton denomina: conformismo, innovación, ritualismo, retraimiento y rebelión. 
Luego de la Teoría de la Anomia de Merton, se pasa a estudiar la llamada Teoría de las

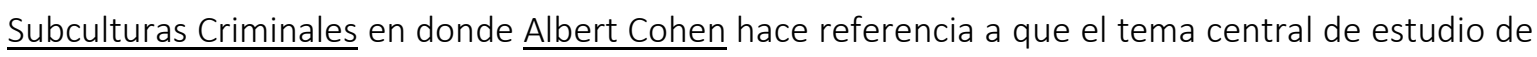
esta teoría es la criminalidad en los grandes centros urbanos. Se hace referencia a los conceptos de desorganización social, retraso cultural y marginalidad. Caracteriza también a esta teoría, el hecho de cuestionar el principio de culpabilidad de las escuelas clásicas y positivistas. Se observa también, que para esta teoría no existe un único sistema oficial de valores sino una serie de subsistemas que $\underline{\text { se transmiten a los individuos. Hay que acotar, que Cohen, limita su estudio a jóvenes delincuentes }}$ provenientes de las clases obreras.

Se habla igualmente sobre lo que Cohen denominó Forma Reactiva, a que la subcultura de los jóvenes es diferente a la de los adultos, al concepto de cultura, a lo que representan las subculturas dentro de la cultura, a las observaciones sobre las cuales Cohen sustenta su estudio, al rol del sujeto en la estructura social, a la necesidad e importancia del grupo de referencia, al hecho de que el rechazo afianza la referencia, a los efectos de la nueva solución subcultural, a las características que para Cohen presenta la subcultura delincuente. Igualmente, se hace referencia tanto al acto delictivo como al acto desviado, a la subcultura delincuente y a la solución delincuente, a las funciones de la respuesta delincuente y al sistema delincuente de valores.

Y para concluir, se estudia la llamada Teoría de las estructuras de oportunidad diferencial planteada por Richard Cloward y Llord Ohlin, en la cual se estudian las bandas juveniles en base a las oportunidades que la sociedad les brinda para obtener las metas sociales por ella fijada y limitan su estudio a las zonas e individuos de los sectores mas bajos. Se analizan las causas que llevan a la formación de las subculturas delincuentes, también se hace referencia a las diferencias entre aspiraciones y oportunidades legitimas, a los canales para ganar status, a la evolución de la subcultura delincuente, a los medios ilegítimos y la subcultura delincuente, a la influencia del medio social en la respuesta desviante, a la diferenciación subculturas y los tipos de subcultura delincuente (criminal, conflictiva y evasora) y a la persistencia y cambio de la subcultura delincuente.

\section{Escuela Sociológica de Emile Durkheim}

Es considerado el padre de la Sociología Francesa. En sus obras "El Suicidio" y "Dos Leyes de la Evolución Penal" manifiesta su oposición a considerar el delito como una anormalidad social, considerándolo en cambio, como un algo que hace parte de toda sociedad. 
Para este autor, no existía sociedad conocida en la que bajo diferentes formas no se observe una criminalidad más o menos desarrollada. No hay sociedad cuya moralidad no sea cotidianamente violada. Entonces, se debe afirmar que el delito es necesario, que no puede dejar de existir y que viene implícito en la misma sociedad. En consecuencia el delito es normal y si es normal que exista, también es normal que sea castigado. Durkheim, basa su análisis de lo criminal en la Teoría de la Anomia, a la cual define como el debilitamiento de los mecanismos culturales y de las normas dentro de una sociedad, caracterizada por una clara división del trabajo (sociedad industrial) en la cual, las diferencias individuales se intensifican, disminuye la conciencia social y se produce una "Solidaridad Orgánica Imperfecta".

Durkheim, llamó Anomia, a la situación en que se produce un vacio de normas, esto puede ocurrir a nivel de toda la sociedad o a nivel individual, es toda situación de ausencia de pautas, falta de valores. Realmente, el problema central estaría en el debilitamiento de los mecanismos culturales y de normas que implican la medida de la satisfacción de las necesidades y que al no cumplirse o no consolidarse se obtienen grados de comportamiento social desviado.

Entonces, cuando el individuo transgrede las normas y o se aleja de ellas, la respuesta del grupo es la reprobación, los miembros de la sociedad establecen ciertos límites de tolerancia frente a la desviación que al ser excedidos como es el caso del delito dan lugar a que se le solicite el castigo. La sociedad delega dicha tarea a las instituciones estatales reforzándose recíprocamente la conciencia social y el poder estatal. Durkheim, decía que el Delito es una lesión a la conciencia colectiva que la sociedad debe reparar y agrega que la pena debe ser aplicada con la máxima exactitud a la gravedad del delito, ya que sería inexplicable, no cree que el culpable deba pagar una pena porque ha provocado un daño de igual medida Concepción de la pena como una venganza de la sociedad por el daño causado por el acto delictuoso.

Para este autor, el delito y la pena son inseparables, el uno no puede existir sin el otro. Si el delito es algo normal y necesario también lo será la pena o el castigo. En efecto, para Durkheim, el control es un mecanismo normal, natural y necesario para mantener el equilibrio y asegurar la evolución de la sociedad; en tanto que la Pena es un castigo que la sociedad debe vengar, el castigo restablecerá el orden jurídico y servirá de medio intimidatorio frente a los demás. Se observa que Durkheim comparte la opinión de Becaria en cuanto a la concepción moralista utilitarista de la pena al usarla como medio moral de reglamentación de la vida social y como medio para la conservación del orden jurídico social establecido, es decir, la pena como medio intimidatorio. 
Durkheim, rechazó toda explicación de carácter patológico en la conducta desviada. Una situación de anomia, es probable en una colectividad social, cuando existen particularidades que obstaculizan la duración y la estabilidad de las relaciones sociales. Estas circunstancias producen desintegración social, es decir el debilitamiento del soporte afectivo que el grupo pudiera otorgar a sus integrantes y eso obliga al aislamiento de algunos de ellos. González Vidaurri y Sánchez Sandoval sostienen que en Estados Unidos y los países de habla inglesa, el concepto de anomia se comprende dentro de una dimensión psicológica que implica pesimismo, desesperanza, alienación. Quizás por eso, allá, el concepto de anomia, se atribuyo no a la estructura social sino al comportamiento de las personas, ante la falta de congruencia entre las metas de éxito propuestas culturalmente y los medios jurídicos existentes para alcanzarlas.

\section{La Escuela Ecológica de Chicago de Shaw y Mckay}

\section{Principales Postulados}

Como es sabido, La Ecología, es una rama de la biología que se encarga del estudio de los hábitos y modos de vida de los organismos vivos, en relación con el ambiente que los circunda. En tanto que, la Ecología Humana, estudia las relaciones ambientales entre las personas y el espacio social. Mientras que la biología y la antropología están en estrecha relación con la psicología y la psiquiatría, la perspectiva ecológica está fuertemente ligada con la Sociología. La Escuela Ecológica de Chicago, se caracteriza por vincular el desarrollo urbano con los procesos ecológicos.

La ciudad brinda refugio y a la vez, mayores posibilidades de desarrollo a los desviantes, pero estas oportunidades que no le son brindadas en las pequeñas ciudades, le permiten en cambio, en la gran ciudad concentrarse en determinadas zonas por razones de comodidad o de afinidad. Shaw y Mckay, estudian las áreas urbanas y su relación con la delincuencia y otras manifestaciones consideradas típicas de las llamadas zonas de desorganización social.

Este enfoque intenta generalizar a partir de los estudios hechos en la ciudad de Chicago, algunos patrones de conducta de ciertas zonas dentro de la misma, a medida que se aproximan o alejan del centro, considerando especialmente las relaciones que había entre la ubicación de tales zonas, la incidencia delictiva y otras formas similares de desviación. Este enfoque, es una postura sociológica, cuyo tema básico es LA DESORGANIZACION SOCIAL DE LAS CIUDADES, principalmente norteamericanas de los años 30', como Detroit o Chicago, que crecían en forma desordenada por la gran migración europea. 
Entonces, esas ciudades se caracterizaban por el riesgo de una fuerte desorganización social y por ello se buscaba un saber práctico para producir el orden en la ciudad. Esto lleva a los criminólogos a convertirse en los nuevos patólogos sociales a objeto de producir una teoría que fuera capaz de encontrar equilibrios bióticos dentro de la ciudad, haciendo que los criminólogos se conviertan en investigadores de campo.

Esta teoría, surge a raíz de las grandes migraciones en Estados Unidos, grandes masas de inmigrantes llegan a USA de diferentes nacionalidades y según los tiempos. Esas grandes masas que llegaban sobre todo a Chicago se ubicaban en una zona de la ciudad, SHAW y MCKAY se dieron cuenta de que esos inmigrantes estaban en una zona de la ciudad que generalmente era vista como la zona de control o de negocios. Ellos, encontraron que la ciudad (la ciudad de Chicago) se podía dividir en zonas concéntricas.

Entonces, la ciudad de Chicago fue estudiada con base a una serie de círculos concéntricos, en los que el corazón de la ciudad lo constituía el área o zona principal o de negocio. Alrededor de ésta, hacia la periferia de la ciudad había zonas de pequeñas fábricas, después estaba la zona de habitación de los obreros, más allá la de los hombres de negocios, enseguida el área industrial, condominios y finalmente los suburbios. Estos estudios identificaron las características sociales distintivas de cada zona.

Al lado de la zona central o de negocios, había una Zona de Desorganización Social, habían unas clases medias y luego las clases altas. Shaw y McKay, veían que en las Zonas de Desorganización Social, había gente que tenia tuberculosis, prostitución, drogas, juegos, enfermedades psiquiátricas, etc., inmigrantes y una serie de cosas que no eran normales en la ciudad de Chicago. Shaw y Mckay, decían que la ciudad es como una especie de organismo y el Distrito central, era como la cabeza; o si vemos a la ciudad como una célula el distrito central o zona de negocios constituiría el núcleo de la misma y las cosas que se producían en la zona de desorganización social no se producían en las otras zonas.

Entonces, había una especie de dependencia de las personas con el lugar donde vivian. Es decir que hay un determinismo geográfico que tiene influencia con la conducta desviada. Pero lo que ellos no estudiaron fue que en las zonas de desorganización social, donde todos los que eran "desviados" estaban ubicados, eran zonas que tenían un precio de alquileres muy bajos debido a que el centro comercial o la llamada Zona de Negocios, no permitían por su conformación que viviera gente de clase media y alta porque eran zonas que se habían ido deteriorando, que tenían valor como terreno, pero muy bajo como alquileres. 
Entonces, los inmigrantes iban a parar allí al igual que todas las personas, que por su profesión se iban a aprovechar de la Zona Central de Negocios. Esta Teoría Ecológica, se emparenta con la ecología animal. El principio de la coexistencia local de las especies seria la interdependencia y habría una especie de comunidad biótica entre las sociedades y la naturaleza como si fuera una cadena alimenticia que empieza en la sociedad naturaleza y termina en la ciudad. Ellos extienden la naturaleza a la ciudad. Por eso son positivistas. Es una Escuela biologicísta de alguna manera.

\section{EI CULTURALISMO DE SELLIN}

Sellin, utilizó la expresión conflicto de culturas para explicar la razón de la conducta delictiva que se producía en la ciudad de Chicago. Precisamente, porque hay grandes oleadas migratorias, llegando a la conclusión de que las personas que llegaban a las zonas de desorganización social o a las que Sutherland denominó zonas de asociación diferencial, eran personas que tenían sus propios valores y sus propias culturas y que por lo tanto, estaban en conflicto con la cultura del país de recepción.

Para Sellin, la cultura es considerada de acuerdo a sus propias normas de conducta, de cuyo conflicto nacería el delito. Para este autor los conflictos de culturas son inevitables. El conflicto cultural según Sellin, puede traducirse en violación de las normas, simplemente porque personas que han asimilado las normas de un grupo o de un área cultural emigran hacia otra y tal conflicto durará hasta tanto se haya completado el proceso de absorción o fusión cultural.

Era la segunda generación de inmigrantes, la que tendría más problemas de socialización porque habían asumido a través de los procesos de educación en la familia, los valores de la cultura del país de origen y al mismo tiempo se enfrentaba en la calle, en la escuela a unos modelos culturales diferentes que eran los de la sociedad norteamericana y eso producía una falta de normas. Había tantas normas que obedecer, algunas contradictorias (las de la sociedad norteamericana y las del país de origen) que prácticamente se produce una falta de normas y ese conflicto de normas produce la delincuencia.

Esta Teoría fue propuesta para estudiar el problema norteamericano en la integración de los emigrados a la nueva cultura y sirvió a Sellin, para sacar a la luz la influencia de los factores culturales en la generación de conflictos, no solo de coexistencia entre sistemas de culturas globales o conflictos primarios. Por ejemplo el conflicto entre cultura rural y cultura urbana o cultura europea y cultura americana, sino que también puede constituir causa de conflicto y favorecer la conducta desviada. Los mecanismos secundarios, tales como: el rechazo del grupo, la 
marginación, o la relegación que actúan en situaciones diferentes de la inmigración, que igualmente se traducen en factores de inseguridad y de ansiedad en el individuo. Sellin, puso en evidencia que para lograr una conducta integrada es necesario que exista una sintonía entre valores normativos y culturales del grupo y los de la ley.

\section{LA TEORIA DE LA ASOCIACION SOCIAL DIFERENCIAL DE SUTHERLAND}

Sutherland (1960), parte de que la criminología para que pueda ser considerada como científica, requiere de una recolección heterogénea, requiere también que los múltiples factores que se asocian con el delito deben ser organizados e integrados a través de una teoría explicativa que tenga las mismas características que las explicaciones científicas en otros campos de estudios. Dicho en otras palabras, las condiciones que originan el delito, deberán estar siempre presentes cuando el delito está presente, y deberán estar siempre ausentes, cuando el delito está ausente.

Esta teoría, estimularía, simplificaría y le daría dirección a la investigación criminológica y asumiría un marco para entender el significado de gran parte del conocimiento que se ha adquirido sobre el delito en el pasado. Incluso, sería útil para controlarle, siempre que se pueda "aplicar" de la misma forma en que el ingeniero aplica las teorías científicas del físico. (ANIYAR DE CASTRO, 1973:1).

Es en 1939, cuando Edwin Sutherland platea su teoría para explicar el comportamiento criminal y a la cual denominó "Teoría de la Asociación Diferencial". Sutherland, parte de una concepción culturalista de la desorganización social la cual para él, al igual que para Durkheim y para los llamados chicagons, constituía el síntoma de la ruptura con los viejos cánones culturales y es en este orden, donde comienzan a gestarse los nuevos valores y aparecen los comportamientos desviados y criminales opuestos y negadores de los otros. (SANTOS, 1987:35).

Edwin Sutherland, rechaza la Concepción Patológica de la Criminalidad, se ha salido de las Ciencias Naturales para entrar en el mundo de las Ciencias Sociales. Para Edwin Sutherland, la conducta delictiva no opera por simple imitación de la cultura de otras personas, sino por la asociación interpersonal con delincuentes. El aprendizaje de la conducta esta en relación con la frecuencia, la prioridad, la duración y el tipo de contactos. En algunos grupos, un individuo está rodeado por personas que invariablemente consideran los códigos como un conjunto de normas que deben observarse y respetarse; mientras que existen otros grupos, en los que el individuo puede estar rodeado por personas cuyos conceptos y conductas favorecen la violación de las normas contenidas en esos mismos códigos. 
Como consecuencia de esa asociación con grupos o personas que favorecen la violación de las normas contenidas en esos códigos y normas de conductas socialmente aceptados, un individuo puede convertirse en delincuente aun estando en igualdad de condiciones económicas y sociales con otros individuos que no se relacionan con ese tipo de grupo o personas.

Sutherland, cuando habla de la Asociación Social Diferencial decía que en cada área social hay una pluralidad normativa, gentes con diferentes sistemas de valores, portadores de diferentes sistemas normativos que no son necesariamente los del país donde viven. Como la conducta delictiva se aprende como cualquier otra conducta, la persona podía aprender de esas normas en vez de otras normas, toda va a depender de con quien este en contacto. Sutherland, afirma que LA CONDUCTA DELICTIVA SE APRENDE, pero NO NECESARIAMENTE SE APRENDE A SER DELINCUENTE, en la vida cotidiana se aprende de todo, se aprende en la interacción con otras personas en un proceso de comunicación pero esas otras personas están en grupos íntimos (familia, maestros, muchachos del barrio, etc.) es de allí de donde se aprende.

Por lo tanto, EL PROCESO DE APRENDIZAJE ES PERSONA A PERSONA Y EN GRUPOS ÍNTIMOS. No basta con estar con un grupo de personas para actuar como ellos, es necesario que se aprendan las técnicas, los motivos, los impulsos, las justificaciones (de porque yo lo hago) y las actitudes, todas estas cosas se van a aprender a la vez que la conducta. Como consecuencia de lo anterior, se puede afirmar que Edwin Sutherland, desarrolló un sistema socio-crimino-génesis que puede resumirse así:

1. El proceso que adquiere como resultado un proceso criminal no es diverso de aquel que da origen al comportamiento normal, pues es siempre en el seno de la familia o del grupo, que el sujeto establece su propio esquema de conducta.

2. El comportamiento delictivo es intrínseco al sistema social, constituido por la asociación de personas de diversos tipos igual a lo que sucede para el comportamiento normal. Cada uno de ellos posee y está integrado por un grupo de valores que es respetada por todos sus asociados.

3. La personalidad criminal funciona en el ámbito de estos sistemas, las asociaciones toman vida con base a los intereses propios de una determinada categoría de sujetos. La personalidad criminal esta integrada por asociaciones que persiguen un fin normal e igualmente sucede para la personalidad no criminal. Estas asociaciones tienen una dimensión cultural que les es propia y es por esto, que la cultura criminal aprecia en sentido positivo la conducta antisocial. 
4. Las diferencias individuales juegan un papel muy importante en el futuro del delincuente en la medida en que este participe en la cultura delictiva. Un adolescente está predispuesto al delito más por la influencia de su ambiente familiar, que por su patrimonio hereditario o por su constitución orgánica. Por lo tanto, se puede afirmar que en una satisfactoria integración, en una buena estructura social puede reducir considerablemente la influencia de los factores criminógenos personales.

5. Los conflictos de interés que dan origen a las asociaciones diferenciales, son idénticos a aquellos que provocan el nacimiento de todo tipo de asociación. El hombre en realidad logra muy poco por sus propios medios y es por ello, que siente la necesidad de asociarse a otros que busquen sus mismos intereses comunes.

6. El surgimiento de asociaciones en competencia recíproca, mas o menos violenta, conduce a la desorganización de la sociedad a través del debilitamiento de los valores comunitarios. La disgregación cultural da vida a una subcultura, integrada en un ámbito de valores diversos u opuestos a aquellos de la comunidad.

Por lo tanto, dado que existe en la conducta delictiva determinantes endógenos (propios del sujeto) y determinantes exógenos (socio ambientales), los distintos sistemas de tratamiento de la delincuencia deben actuar no solo sobre el delincuente individual, sino que también deben dirigirse a remover las causas estructurales y funcionales que favorecen la delincuencia.

\section{EL ESTRUCTURAL FUNCIONALISMO}

Dentro del Positivismo, aparece el Esquema Estructural - Funcionalista, que a pesar de ser positivista, comprende la cuestión criminal de otra manera y sostiene que:

1. En la Sociedad, todos son culpables menos el Delincuente.

2. Esta corriente del estructural - funcionalista surgió con la depresión económica de 1929 y saca a la luz pública el desorden que se generó con la crisis.

3. Surge la Teoría de la Desorganización Social.

4. La estructura de poder y la función social o funcionalidad de los órganos de ese poder, es lo que hay que estudiar porque allí están las causas por las que la sociedad se desborda.

El Estructural Funcionalismo, tiene su origen en el evolucionismo biológico - organicista y en la Antropología Social, que consideran a la sociedad como un organismo natural vivo. Su objeto de estúdio, está referido a las estructuras y funciones sociales que dependen de las instituciones públicas y de los individuos en el desempeño de sus roles como parte del todo. El estructural 
funcionalismo, busca las causas del comportamiento criminal pero no en la condición patológica de las personas, sino en la estructura - función de la sociedad. Las Teorías Sociológicas del Estructural Funcionalismo, han considerado el concepto de Cultura y de Subcultura como elementos determinantes en el origen de las desviaciones o control de las mismas.

La Cultura de una Sociedad forma en gran medida la personalidad de sus miembros. A su vez, la Personalidad es el producto de dos (2) elementos: el temperamento, conformado por la carga genética hereditaria de cada individuo y el carácter, conformado desde el momento en que un individuo nace, como producto de las experiencias culturales vividas en la infancia y en la juventud.

En el ámbito de la misma cultura existen diferencias y grados que traen como consecuencia la formación de varias Subculturas que unidas a las diferencias físicas y mentales de los diversos miembros de las mismas, acarrean una múltiple variabilidad de las personalidades humanas. La Cultura, es un concepto relativo a cada grupo social y difícilmente defendible. Desde esta perspectiva, El Delito es considerado como una de las múltiples maneras como pueda expresarse la cultura de una determinada sociedad, ó dentro de esa misma sociedad, la cultura de un determinado grupo. En una sociedad existen tantas culturas, como cuantos sean los grupos que actúan en ella.

\section{La Teoría de la Anomia de Robert Merton}

Es uno de los padres de la Escuela Estructural - Funcionalista. Uno de los más importantes estudios sobre la desviación y el crimen es el de la anomia y estructura social desarrolla por Robert Merton en 1938. Este autor, intenta dar una explicación macro sociológica del comportamiento desviado, recuperando así, el rol explicativo de los estudios puramente empíricos y sectoriales de la sociología anterior. Al igual que Durkheim, Merton desarrolló una interpretación del comportamiento criminal y rechazó cualquier explicación patológica que viniera de la psicología o de la sociología. Para Merton la desviación y el crimen son fenómenos inherentes a cualquier sociedad, siendo ella su fuente originaria.

\section{Diferencia entre Estructura Cultural y Estructura Social}

A los efectos de explicar su Teoría, Merton distingue entre:

1. Estructura Social: Los roles y el status social. 
2. Estructura Cultural: Conjunto de normas que regulan el comportamiento del grupo o de la sociedad.

La Estructura Social, ofrece a los individuos de acuerdo a su pertenecía económico - social, la oportunidad de lograr tanto los fines como los medios legítimos para obtenerlos. En tanto que, la Estructura Cultural, propone los fines fundamentales hacia los cuales se dirige el comportamiento de los individuos y establece, a su vez, los modelos aceptados de comportamiento para acceder a los medios legítimos con los cuales obtener dichos fines. Cuando la estructura social difiere significativamente de la estructura cultural, o lo que es lo mismo, cuando las metas colidan con los medios surge LA ANOMIA. Merton, trata de elaborar una teoría que fuera capaz de explicar cómo son las personas en una sociedad, no solo los delincuentes, sino también las diferentes categorías de personas (burócratas, delincuentes, toxicómanos, etc.)

\section{Marco Histórico}

El marco histórico en el que surge esta teoría sigue siendo el de la Sociedad Norteamericana de los años 20' del siglo XX, es el momento de la gran depresión, de la gran crisis norteamericana de 1929. Como es sabido, fue un momento de grandes crisis, de un gran caos anómico porque Durkheim que fue el que habló de "Anomia" por primera vez, hablaba incluso de suicidio anómico, de la anomia que se produce en épocas de guerra, en épocas de grandes crisis donde las personas no tienen patrones de conducta que seguir, hay una gran desorganización en las normas.

En opinión de Rosa del Olmo (1979) es la década de los años 30, en la que los sociólogos académicos norteamericanos, como consecuencia de la gran depresión sufrida por este país y como consecuencia también, de las crisis sociales que se vivían en la época, aunado, al marcado temor que sentían hacia el marxismo, deciden considerar como necesidad primordial el estudiar el problema de la "desviación de las normas institucionales". Es de aquí que deviene su interés por fomentar reformas y proponer medidas para realizar ciertos ajustes en el orden institucional con el objetivo de minimizar las manifestaciones que ellos denominaban "desorganización social", "conducta desviada" o incluso "anomia".

En el momento de la gran depresión económica, se viene abajo el modelo del sistema productivo norteamericano porque empiezan a quebrar los millonarios y todas las empresas... Entonces, ellos intentan salvar los valores de la cultura norteamericana. Y, Cuales son esos valores?, lo que se ha llamado el sueño americano, dejando claro que no en todos los casos este 
sueño ha sido real, pero en algunos casos es real que se pueda ir desde la cabaña del tío Tom hasta la Casa Blanca...

El sueño americano (correctamente, estadounidense) puede definirse como la igualdad de oportunidades y libertad que permite que todos los habitantes de Estados Unidos logren sus objetivos en la vida únicamente con el esfuerzo y la determinación. Hoy, esta idea expresada por primera vez en 1931 por James Truslow Adams, se refiere a que la prosperidad depende de las habilidades de uno y de su trabajo, no en un sentido rígido de jerarquía social, aunque el significado de la frase ha cambiado durante la historia de Estados Unidos.

Para algunos, es la oportunidad de lograr más riqueza de la que ellos podrían tener en sus países de origen; para otros, es la oportunidad para sus hijos de que crezcan con una buena educación y grandes oportunidades; por último, hay quien lo ve como la oportunidad para ser un individuo sin restricciones impuestas por motivo de raza, clase, religión, etcétera. Esta es la situación que Merton prevé en una sociedad como la Americana que, exalta los valores materiales y la competitividad individualista, creando ella misma (la sociedad) de que es necesario lograr metas a través de cualquier medio para la obtención de un status ideal.

La anomia, para la sociología, es el quiebre de la estructura cultural, que se da cuando hay una disyunción aguda entre las normas y los objetivos culturales, y las capacidades que se estructuran socialmente en los individuos del grupo para obrar en concierto a estos objetivos. (TIJOUX, 2004:1). Durkheim, utilizó el vocablo “anomie" por vez primera en su obra "La División Social del Trabajo" publicada en 1893. Sin embargo, fue en su estudio sobre el Suicidio publicado en 1897, donde Durkheim hace referencia a tres tipos de suicidios: el egoísta, el altruista y anómico. Los suicidios provocados por una situación de anomia que implicaba para Durkheim un estado de "falta de normas" era para él, consecuencia del fracaso de los frenos sociales que lo que podría llamarse ambiciones demasiado presuntuosas. En otros términos, el suicidio anómico, para Durkheim era el producto de obtener todo demasiado fácil y sin la correspondiente regulación. (DEL OLMO, 1979:129)

El concepto de anomia acuñado por Durkheim debió esperar más de 30 años para volver a ser discutido, ya que, no es sino hasta 1929 cuando Pitirim A. Sorokin, retoma el concepto y se refiere de manera detallada al suicidio anómico. En 1933, Elton Mayo, utiliza el concepto de anomia como sinónimo de desorganización social y plantea que es una condición característica de las grandes ciudades industrializadas. Es decir, la anomia se convierte en una causa de los problemas sociales que afronta la sociedad norteamericana y en especial sus grandes ciudades. 
(DEL OLMO,1979:129). Merton, a diferencia de Durkheim, intenta explicar la anomia y su relación con la conducta desviada pero enfocada hacia el orden social y no al individuo.

$\underline{\text { LA ANOMIA para Merton es la discordancia que se produce entre Metas y Medios. Las }}$ $\underline{\text { metas, }}$ son los objetivos que se proponen culturalmente para ser alcanzados por todo el mundo. (Por ejemplo, llegar a la Casa Blanca esa sería la meta, ascender en la clase social lo más posible) y los medios institucionales de que se dispone. Todos, según Merton serian socializados en las metas culturalmente propuestas. Todos son socializados para tener éxito lucrativo, éxito de status. Pero a todo el mundo no le dan los medios para alcanzar esas metas.

En este contexto social de desigualdad (o de desigualdad social), los individuos buscan responder a las exigencias establecidas por el sistema social ya sea:

1. Desviándose de las exigencias establecidas.

2. Conformándose con las exigencias sociales.

Modos de Adaptación

Dice Merton que entre esas metas a las que se presiona alcanzar y los medios que tiene para alcanzarlos se produce un gran desajuste, una brecha, una tensión en la persona que contribuiría a que esas personas llegaran a ser delincuentes.

Sostiene, que para esa tensión, para ese desajuste que se produce, había formas o Modos de adaptación a esa tensión, respuestas que serian: El Conformista, acepta las metas culturales pero acepta también los medios que se le dan. Se podría sintetizar en la siguiente frase: "Para alcanzar el éxito vamos por buen camino, pero debemos seguir trabajando"; El Innovador, acepta las metas culturales pero no acepta los medios y como no acepta los medios utiliza otros medios. El innovador tiende a ser un delincuente porque busca medios que no son los institucionalizados. Se podría sintetizar en la siguiente frase: "Alcanzar el poder y la fama, justifica los medios ilícitos".

El Ritualista, rechaza las metas (no le interesa ser rico, ni tener status, ni prestigio) pero acepta sobre todo los medios. Es la persona que se queda en el rito, en la cosa repetitiva (Ej: esto no tiene sentido porque no lleva a ninguna parte) se queda en su rutina convencional y no busca ascender de ninguna manera. El ritualista, obedece las normas por encima de toda concepción racional y lógica de la conducta. Se podría sintetizar en la siguiente frase: "No me interesa ser rico, lo que quiero es que me dejen seguir viviendo con mi trabajo". 
El Retraimiento, no acepta las metas, no acepta los medios. No le interesan ni el status, ni el prestigio, ni las riquezas. Tampoco le interesan las leyes. Ejemplo, los hippies, las subculturas de la droga que simplemente están en otro tipo de mundo y de sociedad (mentalmente).

Se podría sintetizar en la siguiente frase: "Al diablo lasa falsas expectativas y los falsos caminos para alcanzarlas. Quédense con su bondad ideológica, yo no juego"; La Rebelión, significa aceptar algunas metas no todas y aceptan algunos medios no todos. Allí estarían los revolucionarios. El comportamiento adaptativo de la rebelión supone el desenmascaramiento de la bondad y la virtud tanto de las metas sociales como de los medios existentes para alcanzarlas. Las personas se constituyen entonces en negadoras de esos fines y de esos medios, convirtiéndose en contra poderes que luchan por el cambio total de la estructura de dominación político económica y por la construcción de nuevos valores económicos.

Robert Merton, a partir de su clásica definición de la anomia, genera un cambio sustancial en la consideración de la desviación. La conducta desviada es la respuesta "normal" a ciertas presiones sociales y no como aparecía en épocas anteriores. Su definición de Anomia viene dada por el marco de dos estructuras sociales que están en tensión, a saber, la estructura cultural y la estructura social. La cultural define los fines y objetivos para ser feliz y conseguir el éxito en la vida, y además, los medios que se pueden usar para conseguirlos. La estructura socio-financiera muestra las oportunidades individuales o particulares (grupos) de acceso a esos medios para conseguir el estatus de triunfo social.

Importancia de la Teoría de la Anomia de Robert Merton

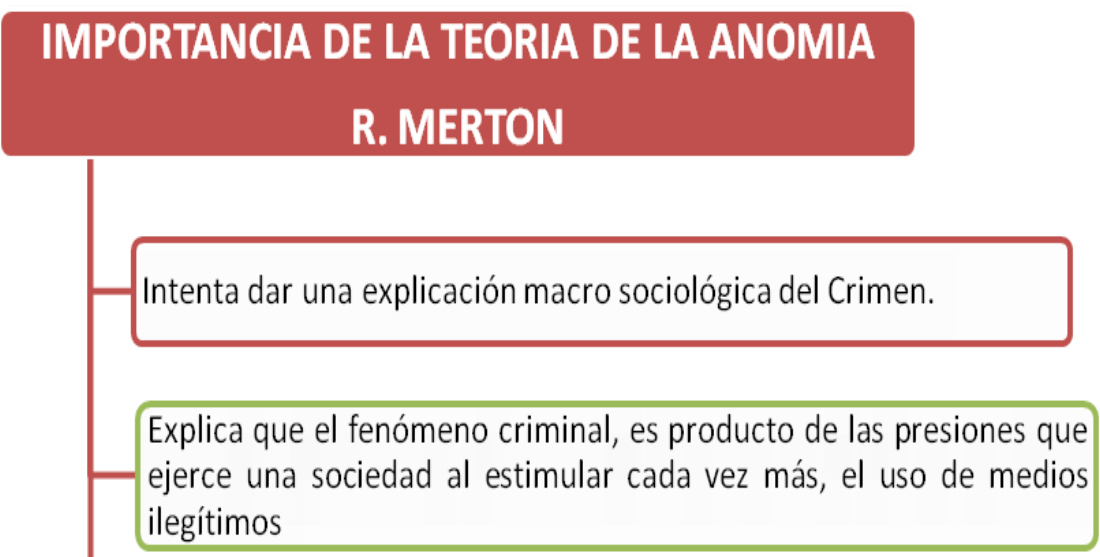

Cambia el concepto de Anomia que anteriormente había dado Durkheim como un defecto de la Sociedad, para convertirla en una acción individual frente a las estructuras sociales. 
Sin embargo, Merton contradice la primera parte de su análisis cuando sostiene que los individuos se alejan de los medios y de las metas legitimas debido a que provienen de los estatus más desfavorecidos de la sociedad, excluyendo casos como el de la Delincuencia de Cuello Blanco, frente al cual Merton nunca estuvo claro y que fundamenta con argumentos ya refutados por sus antecesores, como lo eran los defectos de la socialización. Esto significaba reconocer la vieja tesis de la patología individual como causa del acto delictivo.

Para la criminóloga Rosa del Olmo (1979), la teoría de Merton representa principalmente un proceso acumulativo, debido a que, lo que hace es retomar lo enunciado inicialmente por Durkheim y en donde hacía referencia específicamente al suicidio y lo amplia para poder aplicarlo a todos los tipos de conducta desviada. Su motivación, como el mismo Merton lo manifiesta, fue generada por la concertación que ya habían planteado otros sociólogos norteamericanos que le antecedieron en lo relacionado con el concepto de anomia.

TEORIA DE LAS OPORTUNIDADES DIFERENTES DE RICHARD A. CLOWARD Y LLOYD E. OHLIN

Estos autores afirman que "las áreas de las clases sociales inferiores de los grandes centros urbanos" son la sede de la subcultura delincuencial del adolescente de sexo masculino.

\section{Objetivos, Normas y Anomia}

1. Las causas que llevan a la formación de las subculturas delincuentes provienen de las discrepancias entre las aspiraciones culturales de los jóvenes de clase baja y las oportunidades para alcanzarlas por medios legítimos.

2. Para Durkheim la anomia proviene del fracaso de alcanzar unos objetivos, para Merton proviene del fracaso entre los objetivos y los medios legítimos para lograrlos.

3. Las discrepancias entre las aspiraciones y las oportunidades legítimas aumentan en relación inversa a la clase social. La presión que lleva al comportamiento desviado será más intenso en los niveles sociales bajos.

4. La clase baja descontenta internaliza los valores de la clase media y quiere adoptar su modelo de vida.

5. También Cloward y Olhin se dedicaron al estudio de las bandas juveniles y de los delincuentes adultos pero superando la visión psicologísta de Cohen y centrando la 
atención sobre las oportunidades que la sociedad ofrece para lograr las metas sociales por ella fijadas. Cuando el individuo se siente socialmente estimulado pero no se le ofrecen oportunidades para obtener los fines, se apropia de el un sentimiento de frustración y de rabia que lo conducen a asociaciones que lo impulsan a la desviación.

6. En esta Teoría se revela una variable socio estructural que proviene de la convicción del individuo este en grado de llegar a las metas pero que tienen pocas oportunidades de demostrar su capacidad porque la estructura social solo privilegia a algunos individuos.

\section{Tipos de Subculturas Delincuentes}

Los autores Cloward y Ohlin, presuponen que la persona decide aislarse de la sociedad y unirse a los grupos desviados que pueden clasificarse en tres tipos de subculturas delincuenciales a saber:

1. La Subcultura Criminal, en la cual el sujeto hace del delito su propio modo de vida. Los delitos cometidos, generalmente el robo, el hurto, la extorsión y otros medios ilegales son utilizados para obtener ingresos. El sujeto sigue modelos y roles criminales en un ambiente social que puede ser caracterizado por estrechas relaciones entre menores y adultos delincuentes y entre elementos criminales y convencionales en el área.

2. La Subcultura Conflictiva, en la cual el sujeto recurre a la violencia como vía para obtener una posición social. Es decir que utiliza la violencia en busca de status en condiciones en las que existen severas limitaciones en las oportunidades, sean convencionales o criminales, causantes de frustraciones o resentimientos.

3. La Subcultura Evasora, en la cual el sujeto manifiesta rechazo por los modelos culturales de su grupo y opta por las conductas de aislamiento o retraídas. En esta subcultura se acentúa la desviación del consumo de drogas y el rechazo global de la misma cultura.

Cloward y Olhin, consideran que la estructura social es responsable no solo de la frustración de la posición social del adolescente masculino perteneciente a las clases bajas, sino también de las soluciones, oportunidades, alternativas disponibles. Las "oportunidades disponibles" determinarán cual de las tres subculturas delincuenciales mencionadas tendrán prevalencia en un determinado contexto social.

Estos autores también afirman que el adolescente masculino, perteneciente a las clases sociales bajas se encuentra en una situación anómica, que dadas las circunstancias lo impulsan hacia una u otra subcultura disponible, afirmándose que para que se mantengan subculturas de 
este tipo se requiere la existencia de una interacción de personas que presenten iguales problemas de adaptación. A esta Teoría propuesta por Cloward y Ohlin también se le denomina $\underline{\text { TEORIA DE LA }}$ OPORTUNIDAD DIFERENCIAL.

\section{Teoría de las Subculturas Delincuentes de Albert Cohen}

Albert Cohen, limita su estudio a una muestra de jóvenes delincuentes provenientes de las clases obreras entre quienes identifica su conflicto en relación a su función y su adaptación a los valores de las clases medias. Sí éstas enfatizan los valores individualistas y racionales como: la responsabilidad, la eficacia, el arribismo social y la búsqueda de la propiedad, las clases obreras por su parte, se fundamentan en valores comunitarios y solidarios como el rechazo del hedonismo, de la mentalidad ahorrista y consumista entre otros. (SANTOS, 1987:39). La premisa fundamental que plantea la Teoría de las Subculturas, es que no existe un único sistema oficial de valores, sino una $\underline{\text { serie de subsistemas que se transmiten a los individuos mediante los mecanismos de socialización }}$ y aprendizaje específico del grupo social en el que el individuo está inserto.

Los grupos sociales no son homogéneos, no rigen en ellos las mismas pautas de comportamiento. Cada grupo social, genera su propio sistema de valores, aunque no esté en contradicción con la cultura madre. Cohen define la Cultura, como la participación de cada sector en la elaboración del sistema de normas, influida por la percepción de las mismas normas de los demás autores, que se extiende a todo el sistema social. El termino Cultura, hace referencia a conocimientos, creencias, valores, gustos y perjuicios que son tradicionales en los grupos sociales y que son adquiridos por la participación en dichos grupos. Asimismo, cada sociedad esta diferenciada internamente en muchos subgrupos. La Subcultura, se adquiere por la segregación de los que ya forman parte de la cultura madre y de los desviados que llegan a esa cultura. Para ello, Cohen parte de 2 observaciones a saber:

1. Toda acción humana es un esfuerzo dirigido a resolver problemas. Estos problemas provienen de la situación en la que se halla la individualidad y del "sistema de referencia" o punto de vista ya que los hechos no son contemplados nunca objetivamente. La solución dada depende del punto de referencia, pero si el problema es grave y la solución es inadecuada será necesario un cambio de referencia.

2. Los problemas varían según la posición que ocupa el sujeto en el sistema de clases, por ello, será necesario estudiar el papel de la estructura social en la creación, selección y 
solución de problemas. Cada sujeto tiene un rol en la estructura social, ese rol se le reconoce y respeta socialmente.

Por otra parte, El individuo necesita siempre un Grupo de Referencia que sancione su conducta y le de apoyo. Si la forma de acción que comporta su rol no da solución a sus problemas, buscará otros sujetos con problemas de ajustes semejantes que en interacción entre ellos mediante "gestos de exploración mutua" crearán una nueva forma cultural, con un nuevo sistema de referencia que proporcione soluciones a dichos problemas y que crea una nueva subcultura que sancionará sus actos y en la cual encontrará solución a sus problemas de ajustamiento. Esta nueva solución es subcultural, porque solo estos actores comparten las normas y no todo el sistema social, solo así sobrevivirán. Esta nueva solución subcultural en opinión de Cohen, produce 2 efectos a saber:

1. La hostilidad de quienes están fuera, acentúa la dependencia de los miembros del grupo subcultural.

2. Se acentúa la hostilidad del grupo hacia la Sociedad con el objeto de reafirmarse en sus propios valores.

\section{Características de las Subcultura Delincuente}

Igualmente, Cohen sostiene que la Subcultura Delincuente se caracteriza por ser:

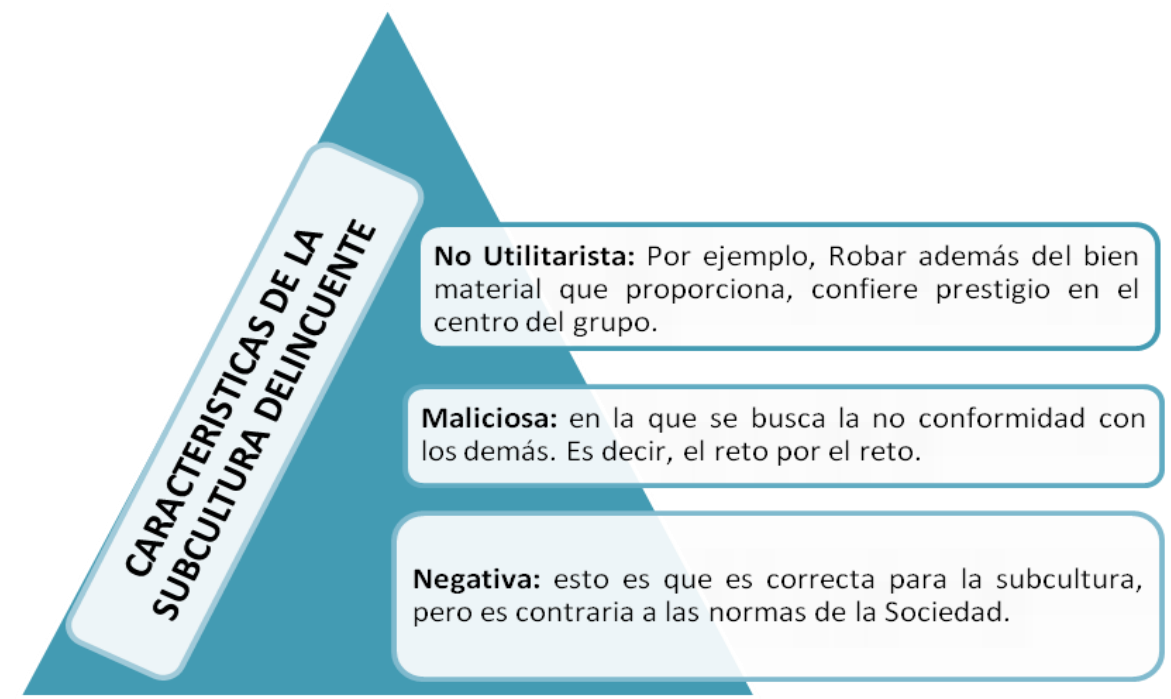

Las Subculturas delincuentes, aparecen en los adolescentes de clase baja en los grandes centros urbanos. 


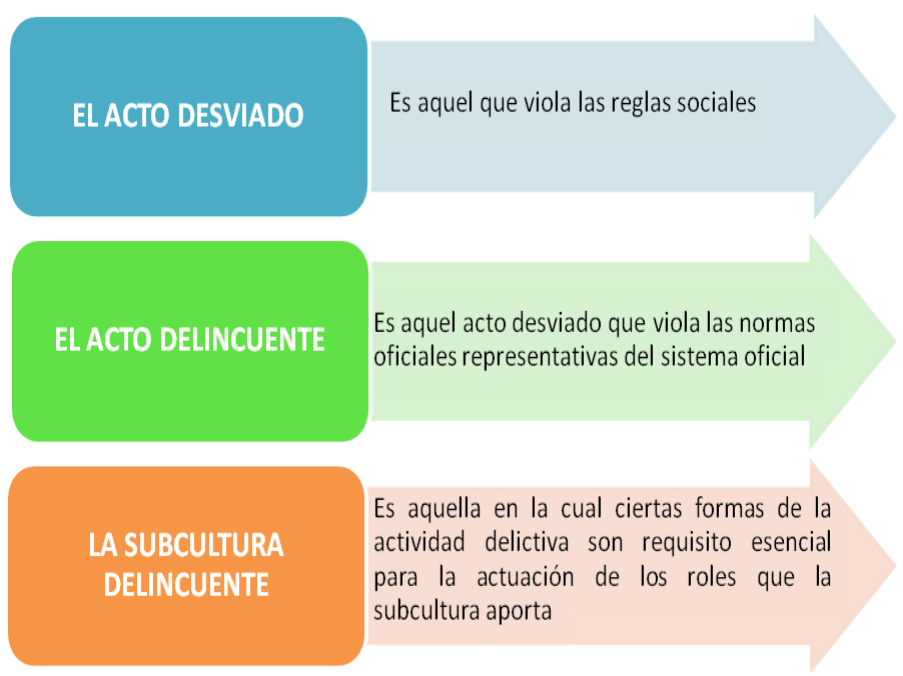

Por otra parte, Albert Cohen, se orienta primordialmente al estudio de la influencia de la estratificación de las clases sociales, en la conducta antisocial de los jóvenes pertenecientes a las clases bajas. Cohen, considera que los jóvenes de la clase media tienen sus problemas particulares, diferentes a los de la clase baja, clase a la que él denomina obrera. En esta clase los problemas son más graves y eficaces para conducir a un sujeto al delito. El planteamiento principal de la Teoría de las Subculturas, es que no existe como ya se mencionó, un único sistema oficial de valores, sino una serie de subsistemas que se transmiten a los individuos, mediante mecanismos de socialización y aprendizaje específico del grupo social en el que el individuo está inmerso. (BARATA,1980:20).

Por lo tanto, los grupos sociales no son homogéneos, debido a que no imperan en ellos las mismas pautas de comportamiento. Cada grupo social genera su propio sistema de valores, aunque no esté en contradicción con la cultura madre. Este orden de ideas, Alessandro Barata (1980) afirma que "que fuera del poder de decisión del individuo y por tanto, también del ámbito de responsabilidad moral, el hecho de pertenecer o no a una determinada subcultura y, en consecuencia, de aprender determinado sistema de valores, o bien determinados modelos de comportamiento desviado, alternativos a los criterios oficiales de comportamiento y valoración".

Cohen, limita su estudio a una muestra de jóvenes delincuentes provenientes de las clases obreras entre quienes identifica su conflicto en relación a su función y su adaptación a los valores de las clases medias. Sí éstas enfatizan los valores individualistas y racionales como: la responsabilidad, la eficacia, el arribismo social y la búsqueda de la propiedad, las clases obreras por su parte, se fundamentan en valores comunitarios y solidarios como el rechazo del hedonismo, de la mentalidad ahorrista y consumista entre otros. (SANTOS,1987:39). 
Frente a estos mundos opuestos, señala Thamara Santos (1987) el adolescente de las clases obreras que debe decidir con cuales valores identificarse experimenta una serie de conflictos como lo son la identificación que implica aceptar un mundo y rechazar otro y el mayor conflicto hace que configure el foco originario de las dificultades de adaptación cuando después de elegir, el joven debe responder a las expectativas que le propone el grupo, con el cual ha decidido identificarse. Una de las respuestas al problema planteado en el párrafo anterior, lo constituye la evasión, es decir, la adhesión a una subcultura delincuente cuyo monolitismo no admite ambigüedades.

Según Cohen, el punto más importante es la toma de conciencia del joven, de la existencia de presión por las diferencias de clases y su influencia en él y en su familia. La ética de la clase media, sus modelos de conductas y valores, difieren en múltiples y variados aspectos, de aquellos pertenecientes a las clases bajas. Las familias de la clase media otorgan mayor importancia a concepto como la ambición, el éxito, la responsabilidad personal, la capacidad de hacer planes racionales y diferir las satisfacciones, los deseos y el control de la agresividad y el respeto a la propiedad ajena. La vida de los jóvenes de clase media es menos limitada o restringida a relaciones primarias de grupo, por ello, tiene mayor facilidad para entablar relaciones de tipo secundario.

Cohen, afirma que de una manera u otra, los valores del joven de clase media son impuestos al joven de la clase obrera (es decir, al joven de la clase baja), la coexistencia de diversos status y sistemas de valores en la vida del joven de clase obrera y de su familia, llevan inevitablemente al conflicto y a la confusión, especialmente, si los jóvenes de la clase obrera no desean rechazar los valores y modelos de la clase media.

Cohen, elaboró una tipología de delincuentes juveniles, siendo cada uno el resultado de diversos tipos de causas, tipologías a las que denominó:

1. Delincuentes prevalentemente subculturales.

2. Delincuentes prevalentemente psicógenos.

3. Delincuentes de tipo mixto. En el que se mezclan factores subculturales y psicógenos, en un único proceso causal.

Principales Lineamientos de la Teoría de las Subculturas Delincuentes

Sobre la Teoría de las Subculturas delincuentes de Cohen se puede puntualizar lo siguiente: 


\section{PRINCIPALES LINEAMIENTOS DE LA TEORÍA DE LAS SUBCULTURAS DELINCUENTES DE COHEN}

Es una teoría propia de los muchachos de clase baja, clase social a la que Cohen denomina obrera.

La Mujer no participa en dicha subcultura.

Es poco frecuente que el muchacho de clase trabajadora adopte una solución individual.

El adolescente de clase media, por lo general no participa de esa subcultura

\section{CONCLUSIONES}

Es muchas veces difícil tomar una posición en cuanto a las bondades de una postura doctrinaria dada, sobre todo cuando esta aparece en la génesis vigente de una rama tan diversificada doctrinariamente como las teorías que tratan de explicar la conducta desviada y aquella que transgrede las normas formales para la convivencia de una sociedad en una dimensión recta o al menos controlada.

Afortunadamente se nos presenta un abanico de posibilidades para poder escoger entre ellas y tomar partido en sus aportes, virtud esta posible en la presente rama del conocimiento ya que cada una de ellas puede convivir con las otras y dar una explicación a una situación determinada, conocer la real esencia de las cosas, siempre según su punto de vista en explicación de cada caso en particular y las razones que puedan privar en el espíritu de cada teoría al momento de su aparición, mas aun si se trata de conductas sociales.

Debe ofrecérsele a la sociedad en general, ultima victima de la transgresión de la norma una explicación concreta y manejable acerca de importancia en el serio análisis de la conducta desviada y una propuesta acerca de su esencia para llegar a su raíz y proponer medidas alternativas a la misma, como siempre ha sido el desiderátum de los códigos y las normas formales de convivencia social, por tal motivo debe en la medida de lo posible ayudarse a la misma, pero en 
forma real y en concreción con el daño ocasionado una explicación científica, ya que los bienes jurídicos lesionados por aquellos son casi siempre imposibles de restaurar, sino de compensar, resaltándose así las virtudes de las mismas y estudiando sus aspectos mas resaltantes, sus criticas, los recursos o beneficios intrínsecos y sus beneficios para los operadores de la justicia y el control social.

\section{REFERENCIAS BIBLIOGRÁFICAS}

ANIYAR DE CASTRO, Lola (2010) Criminología de los Derechos Humanos. Criminología Axiológica como Política Criminal. Editores del Puerto. Buenos Aires, Argentina.

(2003) Entre la dominación y el miedo. Ediciones, Nuevo Siglo C.A. Mérida, Venezuela.

(2003) Resumen Gráfico del Pensamiento Criminológico y su Reflejo Institucional. Ediciones, Nuevo Siglo C.A. Mérida, Venezuela.

(1992) Democracia y Justicia Penal, Ediciones de la Universidad del Zulia, Maracaibo, Venezuela.

(1982) La Realidad contra los mitos. Reflexiones críticas en criminología. Universidad del Zulia. Instituto de Criminología Dra. Lolita Aniyar de Castro. Maracaibo, Venezuela.

(1977) Criminología de la Reacción Social. Universidad del Zulia. Instituto de Criminología Dra. Lolita Aniyar de Castro. Maracaibo, Venezuela.

BARATTA, Alessandro (2009) Criminología Critica y Critica Del Derecho Penal. Siglo XXI Editores. Octava reimpresión. México.

(1985) Requisitos Mínimos del Respeto de los Derechos Humanos en la Ley Penal. Publicado en Revista Capitulo Criminológico Núm. 13. Universidad del Zulia. Instituto de Criminología Dra. Lolita Aniyar de Castro. Maracaibo, Venezuela.

(1984) Criminología y Dogmática Penal. Pasado y Futuro del Modelo integral de la Ciencia Penal. Derecho Penal y Criminología, №. 24: 74 -85. Colombia.

BECARIA, Cesare (1996). De los delitos y de las Penas. Editorial Alianza. Novena reimpresión. Madrid, España.

ELBERT, Carlos (2005). Manual Básico de Criminología. Editorial TEMIS S.A. Bogota, Colombia.

FERRAJOLI LUIGI (1999). Derechos y Garantías: La Ley del más débil. Editorial Trotta. Madrid, España (1997) Derecho y Razón. Teoría del Garantismo Penal. Segunda Edición. Tomo I. Editorial Trotta. Madrid, España.

(1986) El Derecho Penal Mínimo. Poder y Control. Barcelona, España

FLORES CAZORLA, Carmelo (2009) Lecciones de Criminología. 4ta Edición. Vadell Hermanos Editores. Caracas, Venezuela.

GOMES GRILLO, Elio. Criminología.

GARCÍA DE MÁRMOL LEÓN, Carmen. (2009) Criminología. Edición Actualizada. (6ta Edición) Fundación Mármol \& Mármol. Caracas, Venezuela. 
GONZÁLEZ VIDAURI, Alicia y SANDOVAL AUGUSTO, Sánchez. (2005) Criminología. Editorial Porrua. México.

HULSMAN, Louk. (1989) La Criminología Crítica y concepto de delito, en Abolicionismo penal, trad. Mariano A. Ciafardino y Mirta Lilian Bondaza. EDIAR, Buenos Aires, Argentina.

LARRAURI, Elena (1992) La Herencia de la Criminología Critica. 2da Edición. Siglo Veintiuno de España Editores. Madrid, España.

LEAL, García y LUISA, Adela (2005) "Criminología Crítica y Garantismo Penal" en Capítulo Criminológico Revista de las disciplinas del Control Social Vol.33 № 4. del Instituto de Criminología Dra. Lolita Aniyar de Castro de la Facultad de Ciencias Jurídicas y Políticas de la Universidad del Zulia. Maracaibo, Venezuela

MARTínEZ, Mauricio (1992) ¿Hacia Dónde va la Criminología Contemporánea? Publicado en Revista Capitulo Criminológico Núm. 20. Universidad del Zulia. Instituto de Criminología Dra. Lolita Aniyar de Castro. Maracaibo, Venezuela.

PÉREZ PINZÓN, Álvaro y Pérez Castro, Brenda. (2009) Curso de Criminología. Octava Edición. Editorial TEMIS. Bogotá, Colombia.

ROSSELL, Jorge (2002) El Estado Social de Derecho y los nuevos Límites del Derecho Penal. En Capitulo Criminológico Revista de las disciplinas del Control Social Vol.30 № 1 del Instituto de Criminología Dra. Lolita Aniyar de Castro de la Facultad de Ciencias Jurídicas y Políticas de la Universidad del Zulia. Maracaibo, Venezuela

(1986) La realización de los derechos humanos y el uso alternativo del Derecho. Publicado en: Capítulo Criminológico Revista de las disciplinas del Control Social № 14. Del Instituto de Criminología Dra. Lolita Aniyar de Castro de la Facultad de Ciencias Jurídicas y Políticas de la Universidad del Zulia. Maracaibo, Venezuela

SÁNCHEZ SANDOVAL, Augusto (2005). Sistemas Ideológicos y Control Social. Instituto de Investigaciones Jurídicas. Serie Doctrina Jurídica, Num.227. Universidad Autónoma de México. México.

SANDOVAL HUERTA, Emiro. (1989) Sistema penal y criminología crítica. Editorial Temis, Bogotá, Colombia.

SANTOS, Thamara. Control Social y Punición. Instituto de Criminología Dra. Lolita Aniyar de Castro de la Facultad de Ciencias Jurídicas y Políticas de la Universidad del Zulia. Maracaibo, Venezuela

TOCORA, Fernando (1997) Política Criminal Contemporánea. Editorial TEMIS S.A. Santa Fé de Bogotá, Colombia.

ZAFFARONI, Eugenio. (2009) En busca de las penas perdidas. Editorial Editar. 5ta reimpresión. Buenos Aires, Argentina.

(2008) Hacia dónde va el Poder Punitivo. Lemoine Editores.

(1982) Política Criminal Latinoamericana. Editorial Hammurabí, Buenos Aires, Argentina. 
Revista de Direito da Cidade

vol. 07, no 4. Número Especial. ISSN 2317-7721

DOI: $10.12957 /$ rdc.2015.20906

ZAMBRANO, Freddy (2010) Criminología. Editorial Atenea C.A. Caracas, Venezuela.

Trabalho enviado em 14 de agosto de 2015.

Aceito em 19 de setembro de 2015. 